\title{
Status of the Short Dipole Model Program for the LHC
}

\author{
K.Artoos, L.Bottura, P.Fessia, D.Perini, S.Sanfilippo, N.Sjegel, A.Siemko, D.Tommasini, I.Vanenkov, L.Walckiers, C.Wyss \\ CERN, Geneva, Switzerland
}

\begin{abstract}
The model program for the LHC main dipoles is dedicated to the study and validation of design variants and assembly parameters to achicve reproducible performance and optimise components and assembly costs. The topics inyestigated in the last year include the material of the coil end spacers, the use of polyimide films from different manufacturers, the definition of optimum azimuthal and longitudinal coil pre-stress values, shimming of coil ends, collaring around the "cold bore" and different layouts of the yoke ends. This paper presents the main characteristics of such recent models, the results obtained during cold tests and the plans for the final phase of the modes program for the LHC dipoles.
\end{abstract}

\section{INTRODUCTION}

The main features of the $1-\mathrm{m}$ long dipole models made in the course of the LFC short dipole model program till 1998 and the results obtained are described in [1] and [2]. In particular the outcome of this activity led to the present design based on austenitic steel collars and a 6-block coil cross section [3].The most recent single aperture models, here below called S17 to $\mathrm{S} 23$, bave been dedicaled to qualify different options for the series production and to define the nominal values of azimuthal and axial coil pre-stress.

\section{FEATURES OF ReCENT MODELS}

Five single aperture magnets are presented in this paper, some of them re-worked into different versions, totaling 12 units. All magnets features the nominal 6-block coil cross section and austenitic steel collars, with the exception of S17.V3 and S17.V4 which have aluminium collars. The main parameters of the model magnets are recalled in Table I.

TABLE I

MAIN PARAMETERS OF RECLNT SHORT DIFOLE MODELS

\begin{tabular}{ll}
\hline Coil inner diameter & $56 \mathrm{~mm}$ \\
Coil length & $1080 \mathrm{~mm}$ \\
Cable mid-thickness /strands (inner layer) & $1.90 \mathrm{~mm} / 28$ \\
Cable mid-thickness /strands (outer layer) & $1.48 \mathrm{~mm} / 36$ \\
Number of tums (inner/outer layer) & $15 / 25$ \\
Conductor blocks (inner/outer layer) & $4 / 2$ \\
Operating temperature & $1.9 \mathrm{~K}$ \\
Nominal field & $8.33 \mathrm{~T}$ \\
Nominal current & $11.8 \mathrm{kA}$ \\
Nominal short sample field limit & $9.7 \mathrm{~T}$ \\
Ratio peak field to central field & 1.03 \\
\hline
\end{tabular}

The main specific features characterizing these units are summarized in Table II.

Manuseript received on 27 September 1999
TABEE II

SPECIFC FEATURES OF RECENT UNTY'S

(PEI stands for Polyetherimide)

\begin{tabular}{|c|c|}
\hline Magnet & Specific feature \\
\hline S17. $\mathrm{V2}$ & quench heaters added between coil layers \\
\hline$\sqrt{3}$ & add. insulation between quench heaters and coil \\
\hline$\sqrt{4}$ & increased axial load on coil ends \\
\hline S19. V1 & moderate azimuthal pre-stress on inner layer \\
\hline V2 & higher azimuthal coil pre-stress on inner layer \\
\hline V3 & ferromagnetic yoke in coil ends region \\
\hline V4 & collaring around the cold bore \\
\hline S21. V1 & PEI coil end spacers \\
\hline V2 & innermost PEJ spacers replaced by G-11 spacers \\
\hline S22. V1 & PEI coil end spacers \\
\hline S23, V1 & alternative source of polyimide films \\
\hline $\mathrm{v} 2$ & increased axial load on coil ends \\
\hline V3 & higher azimuthal pre-stress in coil ends \\
\hline
\end{tabular}

\section{FaBRICATION DETAIL $S$ \& TEST RESULTS}

\section{A. Quench heaters studies}

To study the correlation between position and layout of quench heaters, magnet protection parameters and temperature profiles, two variants of $S 17$ have been implemented. In the first one (S17.V2) heating strips were added between the inner and the outer layer, facing the outer layet, and in the second one (S17.V3) an additional $125 \mu \mathrm{m}$ thick polyimide sheet was inserted between the standard heaters (placed on the outer side of the outer layer) and the outer layer. These two versions are schematically represented in Fig. 1 .

The results of these two variants are discussed in detail in [4]. In particular, quench heaters located between the inner

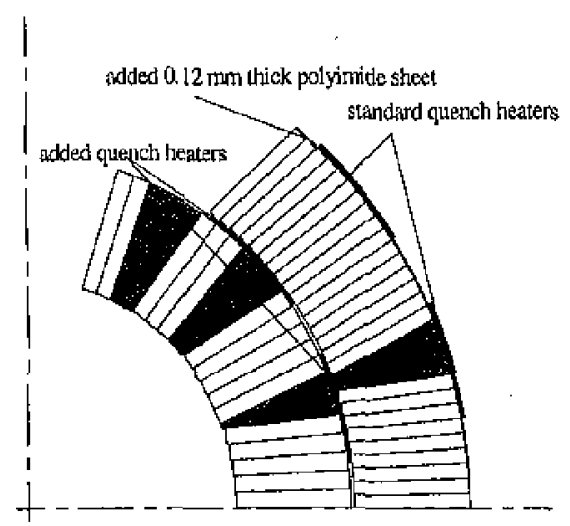

Fig. 1: Schenatic benter layout for S17.V2 and S17.V3 
and the outer coil layers revealed to be more efficient in quench protection then the standard outer layer quench heaters. At high currents (I > $12000 \mathrm{~A}$ ), a reduction by $35 \mathrm{~K}$ of the temperature occurring in the hottest turn and a decrease by $20 \mathrm{~K}$ of the temperature difference across the hottest block were observed. Protection by such type of heaters limited also the increase of peak temperatures in the outer layer, thus reducing the thermo-mechanical stresses causing detraining.

\section{B. Increased axial load on coil ends}

This test was carried out to verify the robustness of the coil ends to axial forces and to identify the allowed range of axial pre-load for long magnets. In the magnets S17.V4 and the S23.V2, the axial pre-load was increased from $4 \mathrm{t}$ to about 10 t after a first training run followed by a thermal cycle.

The test results show that magnets with higher axial preload have a higher first quench field level (by about $0.7 \mathrm{~T}$ for $\mathrm{S} 23$ and by $0.3 \mathrm{~T}$ for $\mathrm{S} 17$ ) and a shorter training (9.7T was reached after 10 quenches for $S 23 . V 1$ and already at the second quench for $\$ 23 . \mathrm{V} 2$, after 14 quenches for $\$ 17 . \mathrm{V} 3$ and after 6 quenches for S17.V4). However no conclusions between improved performance and higher axial load can be drawn yet, because the magnets were not de-collared prior to increasing the axial load. The better performance may stem from the training run to which they were submitted first.

In fact, the axial pre-load increase did not change the weak points and the quench Jocation. For S23.V2, for example, the first quenches remained located in the ends of the outer layer at the non-connection side. It was however observed for this magnet that the higher axial pre-load weakened the central part of the outer layer and fayored mechanically induced quenches in this region. As a conclusion, further work is required on this matter.

\section{Collaring around the cold bore tube}

For the LHC dipoles, the insertion of the $16 \mathrm{~m}$ long cold bore into the collared coils aperture as the before last step of the collaring procedure, after removal of a collaring mandrel, is a delicate and time-consuming operation. An alternative would be to assemble the coils around the cold bote tube and use it as a collaring inandrel. This procedure was already tested in 1996 on a 5-block coil cross section magnet, with excellent resilts. The same has been now done on the standard 6-block geometry model $\$ 19 . \mathrm{V} 4$. The standard vacuum tube $(0.4 .53 \mathrm{~mm})$ was insulated with a polyimide layer and G11 fish-bones like spacers, to increase its outer diameter to $55 \mathrm{~mm}$. Longitudinal helium venting between the tube and the coil is obtained by the channels in the fish-bone spacers and by the $0.5 \mathrm{~mm}$ clearance between tube and coil aperture. The tube is centred inside the aperture by the coil ground-insulation polyimide sheets $(4 \times 125 \mu \mathrm{m})$ protruding into the aperture over an azimuthal length of $10 \mathrm{~mm}$, along both sides of the collar noses.

No clear change was observed in terms of training and quench location. The magnet trained like the previous version $S 19, \mathrm{~V} 2$ and reached the same maximum magnetic field
(10 T). Weak points and quench locations were the same, but the level of the first quench $(7.65 \mathrm{~T})$ was $0.8 \mathrm{~T}$ below that of S19.V2. However, such field level differences at the first quench were observed also on model magnets collared with the standard procedure (making use of an expandable mandrel which supports the coils whilst the collars are pressed against the coils) and therefore no correlation between collaring on cold bore and field level at the first quench can be drawn yet.

The same magnet was then tested again after a thermal cycle. For this second test the magnet was not de-collared and a LCH beam screen was inserted inside the cold bore. The first quench occurred at $9.37 \mathrm{~T}$, the best value ever obtained for short models. The second one occurred at $9.83 \mathrm{~T}$, i.e. $0.15 \mathrm{~T}$ below the maximum magnetic field achieved by the previous versions. These results show that collaring around the cold bore did not impair magnet performance.

\section{PEI coil end spacers}

One inner and one outer layer require each 13 different major end spacers between layer blocks, five minor ones (the chips and the wedge tips between turjs of a same block), and four large saddle end-pieces confining the outer turns of each layer. Coil end spacers are traditionally manufactured out of G11. The machining of the required 3-D surfaces to a precision of a few tenths of $\mathrm{mm}$ is relatively expensive. Manufacture by injection molding is a very cost-effective alternative, provided adequate materials can be qualified. Polyetherimide (PEI), a thermoplastic material which can be charged with glass-fibres from 10 to $40 \%$ in weight, was tested first. The above major and minor end spacers were manufactured successfully, whereas the large saddle endpieces, because of their dimensions and wall thickness (15.4 mm), could not be easily injection molded to the required density, as shown by ultrasound inspection. A possible solution was found in increasing the injection speed and pressure by using more complex moulds. Taking into account the higher tooling cost and the smaller number of pieces achieved per injection cycle, the economical advantage of injection molding with respect to machining showed to be marginal for these large pieces. On the other hand injection moulding is perfectly suitable for the major and minor endspacers, in particular for the latter ones which are extremely difficult and long to be machined. PEI major and minor end spacers were used in the S21.V1 and S22.V1 models. These magnets showed a poor training, they had their first quench at $5.9 \mathrm{~T}$ and $7.0 \mathrm{~T}$ and tequired eight and five more quenches to reach the nominal $8.3 \mathrm{~T}$, respectively. Nearly all quenches occurred in the curved part of the coil ends, while a few ones occurred also in the cetitral part of the inner layer. The conclusion is that performance was limited by mechanically induced quenches, probably caused by movements in the coils ends. Possible explanations for this behavior are the low Young modulus of PEI (about $9.5 \mathrm{GPa}$ at $20^{\circ} \mathrm{C}$ for PEI charged with $30 \%$ of glass-fibre in weight) compated to that of G-11 (about $28 \mathrm{GPa}$ ) and, most probably, the higher thermal contraction of PEI (about twice the G-11 one). 
The S21.V1 magnet was re-worked into S21.V2 by replacing the large innermost spacers of the outer layer, nonconnection side, by a conventional G-11 spacer. The training performance improved considerably, the first quench was at $7.5 \mathrm{~T}$ and two more quenches were required to reach nominal fjeld. Nevertheless, the overall performance of S21.V2 was well below that of magnets with $G 11$ end spacers. It was therefore decided to use in the subsequent model magnets G11 material for the major end spacer and PEI or better only for the minor ones.

As an alternative to PEI, Polyarylamide (PAA) will be tested, for the minor end spacers only, in the forthcoming months. PAA charged with $50 \%$ glass-fibre shows a Young modulus at room temperature of $20 \mathrm{GPa}$ and a thermal contraction from ambient temperature to $1.9 \mathrm{~K}$ nearer to that of $\mathrm{G}+11$.

\section{E. Alternative source of polyimide films}

The purpose was to validate, in terms of training performance, APICAL ${ }^{\text {tM }}$ polyimide plain and adhesive lapes, supplied by KANEKA, for cable and ground insulation. Most short and long models made use of KAPTON ${ }^{\mathrm{TM}}$, supplied by DUPONT, with good results. Among recent magnets, the \$23, in all its versions, was made using APICAL ${ }^{\text {TNA }}$.

The cable insulation consists of two layers of $11 \mathrm{~mm}$ wide, $50 \mu \mathrm{m}$ thick polyimide tape and one layer of $9 \mathrm{~mm}$ wide, $68 \mu \mathrm{m}$ thick adhesive tape. The adhesive, of polyimide formulation, coats the outside of the tape, to bond adjacent coil turns together. The ground insulation consists of four $125 \mathrm{~m}$ thick polyimide sheets, placed between the collars and the insulated quench heaters.

The test results show that the use of APICAL ${ }^{\text {TM }}$ does not modify the usual training performance. In fact, S23.V! belongs to the best performing short models with a first quench at $8.62 \mathrm{~T}$, a second quench at about $9 \mathrm{~T}$ and a quench limit of $9.96 \mathrm{~T}$.

\section{F. Ferromagnetic yoke laminations in coil end region}

The magnetic yoke of the LHC dipole magnet is terminated at both ends, over a length of about $0.5 \mathrm{~m}$, by non-magnetic laminations so as to lower by some $15 \%$ the field at the coil ends. The ends are by design structuraliy less robust than the coil straight regions, are therefore more sensitive to Lorentz forces and quite often show the first training quenches of a magnet. To better understand this sensitivity, magnet S19.V3 has been assembled with a full-length ferromagnetic yoke, encompassing the coil ends. Because of the higher magnetic field in the coil ends, the quench performance was significantly lower, with the first quench at $8.15 \mathrm{~T}$, i.e. $0.9 \mathrm{~T}$ below the first quench of $\$ 19 . \mathrm{V} 1$. Further, the training curve of $\mathrm{S} 19 . \mathrm{V} 3$ was globally lower by $0.45 \mathrm{~T}$ in average than that of S19.V1.
Quenches were mainly located in the ends of the coils at the non-connection side. This clear unbalance between connection and non-connection side in terms of quench bchavior is not fully understood yet.

\section{G. Higher azimuthal pre-stress in coil ends}

The coil ends of all short dipoles are usually shimmed in the mid-plane to obtain, after collaring, an azimuthal prestress comparable to the stresses exerted by the Lorentz forces. As a result, the coils are shimmed progressively from the reference coil pre-stress of the straight section to about $20 \mathrm{MPa}$ (Fig.2). With austenitic steel collars, this pro-stress decreases from ambient temperature to $1.9 \mathrm{~K}$ by more than

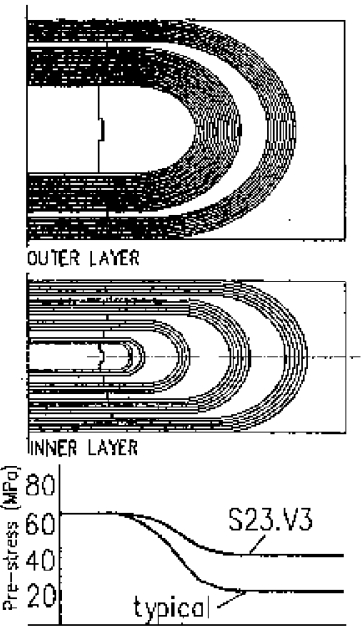

Fig. 2 :Coil pre-stress profile in the heads after collaring

$50 \%$, resulting, if no measure is taken, in a low end pre-stress during magnet operation.

Magnet S23.V3 has been re-collared with the coil ends shimmed to a higher azimuthal pre-stress, by decreasing the gradient of the longitudinal pre-stress.

The training of $S 23, V 3$ was significantly improved with a first quench at $9 \mathrm{~T}(0.38 \mathrm{~T}$ more than $\mathrm{S} 23 . \mathrm{V} 1)$, a second one at about $9.5 \mathrm{~T}$; the quench limil of $9.96 \mathrm{~T}$ was reached after only seven quenches (15 quenches for S23.V1). Quench locations were similar to those of $\$ 23 . \mathrm{V} 1$ but with less quenches in the coils ends. The first two quenches, although at high fields, were still in the ends, in the innermost tum of the outer layer end at the non-lead end. This weak point will be analyzed in detail in the next models, by measuring the azimuthal pre-stress in the ends with capacitive gauges [S]. Differences in magnetic field levels between the coil ends are being analyzed both with 3D FE computations and magnetic field measurements in the region of the coil cnds. Furthermore a 3-D FEM mechanical computer model has been set up in collaboration with industry to study in detail the behavior of the non-lead end [6]. 


\section{H. Azimuthal pre-stress in the coil straight section}

In the present design azimuthal pre-stresses are $25 \mathrm{MPa}$ at the inner Jayer and $40 \mathrm{MPa}$ at the outer one. With these prestresses, the inner layer unloads at fields of about $8 \mathrm{~T}$, while the outer layer stays loaded up to $10 \mathrm{~T}$. Magnets $\mathrm{S} 19 . \mathrm{V} 1$, S19.V2 and S23.V3 were collared with different pre-stresses at the inner layer. Fig. 3 shows the unloading curves of the inner layer pre-stress, measured with capacitive gauges, as a function of the square of the magnet current. The unloading of the azimuthal pre-stress imparted by the collars occurs at about $7 \mathrm{~T}$ for $\mathrm{S} 23 . \mathrm{V} 3,8.5 \mathrm{~T}$ for $\mathrm{S} 19 . \mathrm{V} 1$ and $9.3 \mathrm{~T}$ for $\mathrm{S19.V2}$, respectively. As shown in Fig.4, S23.V3, which had the lowest inner layer pre-stress, presents the quickest training. The slowest training is that of S19.V2, which had the highest pre-stress in the inner layer. In all three cases nost of quenches, and in particular the first 6 ones of $\$ 19 . \mathrm{V} 2$, are in the straight part of the magnet. However, as this comparison is based only on few magnets, it is foreseen to re-assemble $\mathrm{S} 23$ into a new version with a higher pre-stress in the inner layer, to have a further verification of this effect.

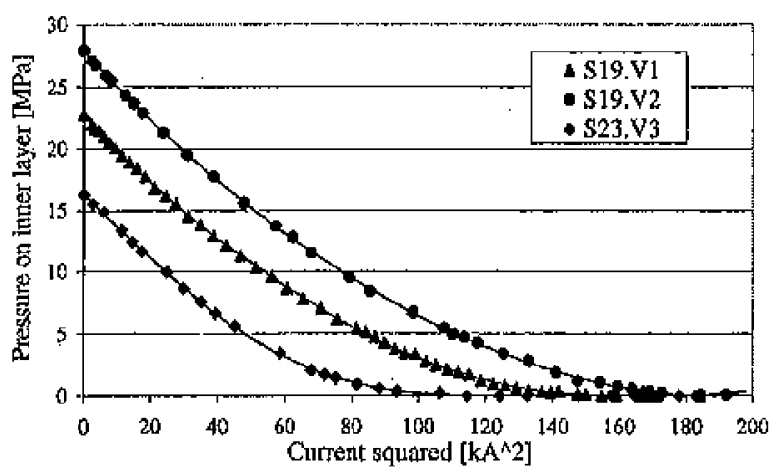

Fig. 3: Azimuthal pre-stress on inner layer during magnet excitation

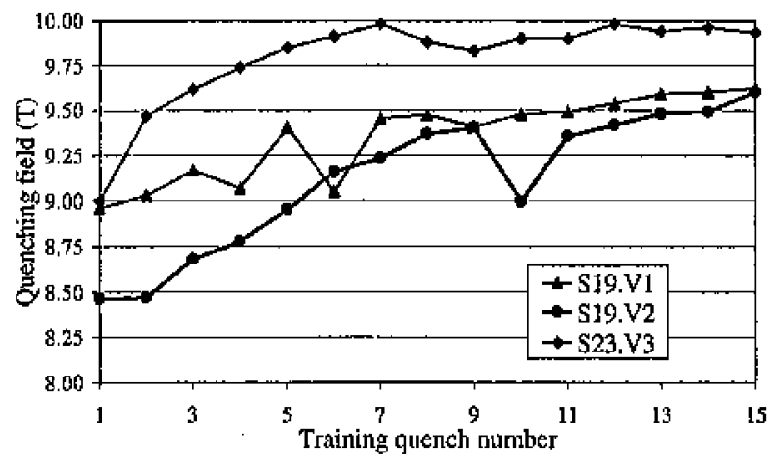

Fig. 4: Training curves of three short dipoles

\section{CONCLUSIONS AND NEXT STEPS}

In addition to the further validation of the 6-block coil design and of the choice of austenitic steel collars, the short model dipole program bas allowed:

a) to asses the merits of placing quench heaters between coil layers; b) to qualify an alternative sonrce of polyimide film for the interturn and ground insulation;

c) to learn that large coil end-spacers made out of PEI material, although pricc-wise attractive, are not suitable;

d) to observe that axial loading does not appear to play a major role in short models;

e) to show that collaring around the cold bore is to be pursued on full-length prototypes;

f) to continue the study of the influence of inner layer azimuthal pre-stress on training behavior;

g) to show that the design of the coil end regions still requires further modeling and experimental work.

The next steps foreseen for the short model program are:

1) the continuation of studies about the design and behnvior of the coil end regions, both on single and twin aperture models (the twin aperture design features, with respect to single aperture one, end fields higher by $0.4 \mathrm{~T}$ and $0.7 \mathrm{~T}$ at the inner and outer layer, respectively);

2) the qualification of PAA as material for small (less than a few cubic $\mathrm{cm}$ ) coil end spacers;

3) the validation of the mixed-material collar-pack concept, whereby the main collars (those locked by the collaring loads) are made out of austenitic steel, whilst the floating ones (those not locked by the collaring rods) are treated as longitudinal spacers and no more as structural components, and could hence be made out of a lighter material [7];

4) optimisation of the yoke layoul in the end regions, with a view to minimise the amount of austenitic steel needed for non-magnetic laminations, reduce the fringe-field and improve field quality at the dipole ends;

5) the manufacture of a small series of identical double aperture magnets to better define reproducibility and standards for quench performance and magnetic field quaity.

\section{ACKNOWLEDGMENTS}

We wish to express our thanks to L.Evans for his support to the short model activity, to the team of the model laboratory for the excellent work and to the teams responsible of cold test and measurements for the close and efficiont collaboration.

\section{REFERENCES}

[1] N.Andreev et al, "The Im Long Single Aperture Dipole Coil Test Program for LHC", EPAC-96, Sitges, Spain, Jnne 1996.

[2] N.Andreev et al., "State of the Short Dipole Model Program for the LHC,", EPAC-98 Stockolm, Sweden, 22-26 June 1998.

[3] N.Andreev et al., "Polf ormance of Five and Six B]ack Coil Geometries in Short Supercondneting Dipole Models for the LHC", PAC-99, New York, USA, March 29th - April 2nd, 1999.

[4] V.Matoussov, S.Sanfilippo, A.Siemko, "Temperature Profiles During Quenches in a LHC Superconducting Dipole Magnets Protected by Quench Heatess", this conference.

[5] I. Vanenkov et al.," Design and Use of Capacitive Force Transducers for Superconducting Magnet Models for the LHC", MT-15, Beijing, 1997.

[6] D, Krischel at al., "Results of 3-dimensional Structural FE-modeling of the Coils End-Regions of the LHC Main Dipoles", this conference.

[7] P.Fessia, D.Perini, Private Communication. 